\title{
Diagnosis and treatment of upper limb apraxia
}

\author{
A. Dovern · G. R. Fink · P. H. Weiss
}

Received: 21 September 2011 / Accepted: 22 November 2011/Published online: 4 January 2012

(C) The Author(s) 2011. This article is published with open access at Springerlink.com

\begin{abstract}
Upper limb apraxia, a disorder of higher motor cognition, is a common consequence of left-hemispheric stroke. Contrary to common assumption, apraxic deficits not only manifest themselves during clinical testing but also have delirious effects on the patients' everyday life and rehabilitation. Thus, a reliable diagnosis and efficient treatment of upper limb apraxia is important to improve the patients' prognosis after stroke. Nevertheless, to date, upper limb apraxia is still an underdiagnosed and ill-treated entity. Based on a systematic literature search, this review summarizes the current tools of diagnosis and treatment strategies for upper limb apraxia. It furthermore provides clinicians with graded recommendations. In particular, a short screening test for apraxia, and a more comprehensive diagnostic apraxia test for clinical use are recommended. Although currently only a few randomized controlled studies investigate the efficacy of different apraxia treatments, the gesture training suggested by Smania and colleagues can be recommended for the therapy of apraxia, the effects of which were shown to extend to activities of daily living and to persist for at least 2 months after completion of the training. This review aims at directing the reader's attention to the ecological relevance of apraxia. Moreover, it provides clinicians with appropriate tools for the reliable diagnosis and effective treatment of apraxia. Nevertheless, this review also highlights the need for further research into
\end{abstract}

A. Dovern $(\bowtie) \cdot$ G. R. Fink · P. H. Weiss

Cognitive Neurology Section, Institute of Neuroscience and Medicine (INM-3), Research Centre Jülich,

Leo-Brandt-Straße 5, 52425 Jülich, Germany

e-mail: A.Dovern@fz-juelich.de

A. Dovern - G. R. Fink - P. H. Weiss

Department of Neurology, University Hospital Cologne,

Kerpener Straße 62, 50937 Cologne, Germany how to improve diagnosis of apraxia based on neuropsychological models and to develop new therapeutic strategies.

Keywords Stroke - Motor cognition - Neuropsychology · Neurorehabilitation

\section{Introduction}

One of the major causes for persistent handicaps and early unemployment in the Western civilization is stroke: about half of the patients surviving a stroke do not fully recover from their stroke but rather suffer from persistent strokerelated sequela [7]. Besides primary sensory-motor deficits (e.g., paresis, deafferentation), a stroke is often accompanied by persistent cognitive deficits: one common cognitive deficit after left hemispheric stroke is apraxia [74], a disorder of higher motor cognition. Apraxic impairments are classified as higher motor deficits since they cannot be fully accounted for by primary sensory and motor deficits, disturbed communication or lack of motivation. The current article focuses on upper limb apraxia, i.e., deficits when carrying out purposeful movements with the arms and/or hands. Frequently observed clinical symptoms of upper limb apraxia are impairments in imitating abstract and symbolic gestures, deficits in pantomiming the use of objects and tools, as well as deficits in actual object use, in particular when complex sequential actions including multiple objects are required. Note that we purposely refrain from using terms like ideo-motor apraxia or ideational apraxia, as the different apraxia classifications are currently under debate $[31,32]$. Instead we describe the various clinical motor deficits of the patients (impaired gesture imitation, pantomiming, and object use), so that the 
reader can classify the apraxic patients to her/his favored classification scheme.

Contrary to a widely held notion, apraxic deficits not only manifest themselves during clinical testing but also have delirious effects on the patients' everyday lives and rehabilitation. As some of the neuropsychological tests used for the diagnosis of apraxia (e.g., pantomiming the use of objects and tools) seem to have no direct bearing on the actual affordances of daily life, apraxia is often considered to have little impact on the patients' everyday lives. However, McDonald et al. [48] reported that apraxic patients make similar errors when actually using objects as compared to pantomiming the use of these objects to verbal command. We are aware that exclusion of body-partas-object (BPO) errors constitutes a limitation of this study and that other studies showed that the kinematics of pantomimed and actual object-related actions may differ considerably (e.g., [41]). However, we would like to stress the fact that apraxic patients ('diagnosed' by their errors in pantomime tasks) also make errors when actually using objects and hence deficits in pantomime performance should not be considered irrelevant for activities of daily living. Moreover, gesture deficits are also of practical significance for the apraxic patient: gesture deficits compromise the patient's communication, as they can no longer be used to compensate for the often concomitant aphasic deficits. For example, apraxia has a negative impact on the quality of communicative gestures [25] and patients affected by apraxia rarely use spontaneous communicative gestures in the natural setting [8]. Furthermore, several studies directly demonstrated the ecological relevance of apraxia by showing that clinical measures of apraxia correlated significantly with the patients' ability to perform several activities of daily living (ADLs), including mealtime behavior [26], bathing, toileting, and grooming [40], as well as dressing and brushing one's teeth [35]. Consistently, apraxia significantly impacts upon neurorehabilitation: with respect to several ADLs, the severity of apraxia determined the dependency of stroke patients on their caregivers after discharge from the rehabilitation clinic [6, 29, 63]. Likewise, stroke patients suffering from apraxia less frequently return to work than stroke patients without apraxia [59]. It is important to note that nearly all studies dealing with the ecological relevance of apraxia used apraxia measures including both meaningful and meaningless items, i.e., measures that assess apraxic impairments of the semantic as well as the structural processing route (see below). Although these studies do not provide any insight into which apraxic deficits (and hence which apraxia tests) predict performance of which specific aspects of everyday life, they clearly demonstrate that apraxia has a more pronounced clinical relevance than is commonly assumed. Thus, the diagnosis of and effective treatment strategies for apraxia are of great clinical importance. With respect to the latter issue, only a few studies with an adequate study design and a sufficiently large patient sample have been published. Nevertheless, these studies indicate that a successful treatment of upper limb apraxia is feasible. Existing treatment options for apraxia in turn trigger the clinical need to correctly identify patients suffering from apraxia, so that the patients can undergo adequate neurorehabilitation programs accounting for apraxia. Thus, reliable and valid clinical tests for the diagnosis of apraxia are required. To date, apraxia is underdiagnosed and the diagnosis of apraxia is often based on the qualitative (not quantitative) judgment of apraxia experts. However, such an approach cannot provide us with quantifiable data (e.g., test scores and cut-offs), which are especially essential when clinicians and researchers plan to undertake clinical studies in apraxia. Moreover, quantitative assessments with good psychometric properties taking into account the different apraxic symptoms would also allow to resolve the question of which specific apraxic deficits would predict performance of which specific aspects of everyday life. Although numerous neuropsychological tests for the diagnosis of apraxia have been published, only a few of these assessments can be considered appropriate for clinical use. For many of these, no psychometric characteristics are available [2, 16, 17, 30, 39, 43, 45, 49]. Furthermore, many assessments do not account for the different aspects of apraxia, but focus on only a single apraxic deficit, e.g., disturbed imitation or impaired object use [16, 19, 24, 30, 52, 53, 57]. Finally, some test batteries are very timeconsuming, which seriously limits their applicability in every-day clinical routines [1, 4, 24, 46, 50, 60]. These important limitations are likely to contribute to the fact that none of these to-date published assessments have become widely accepted as a standard tool for the assessment of upper limb apraxia. The heterogeneity of tools and their limitations also probably account for the variable prevalence rates of apraxia that have been reported in patients with left-hemisphere stroke: ranging from 28 [20] to 54\% [42]. As many of the tests merely examine single aspects of apraxia, it might occur that a given patient may be considered apraxic according to a test that only assesses meaningless gestures, but shows no signs of apraxia in another test that assesses the ability to perform meaningful gestures [34].

With this review we would like to raise the interest of both clinicians and neuroscientists for the syndrome of upper limb apraxia and its clinical relevance. The aim of the current review is to provide an overview on the published tests developed for the diagnosis of limb apraxia. This shall help the reader to select a diagnostic tool appropriate for his/her own needs (e.g., short screening, clinical diagnosis, scientific study). In the second part of 
the review, different approaches for the treatment of upper limb apraxia will be presented and critically evaluated. Here, the focus is on therapeutic interventions that have been examined in randomized controlled trials (RCTs) and thus can be recommended based on strong evidence-based criteria. Note that we do not restrict our review to these evidence-based therapies for apraxia, but also describe further published therapeutic approaches [10], as these might have implications for the development of new therapeutic strategies for upper limb apraxia [72].

\section{Assessment of upper limb apraxia}

During the last four decades, more than 20 assessments for upper limb apraxia have been published. While some of the assessments were developed as a diagnostic tool within the clinical setting, other assessments were primarily developed for scientific purposes. One reason for the high number of different assessments is that apraxia is a very heterogeneous syndrome and many assessments capture merely single aspects of apraxia (e.g., either imitation of gestures or object use) that can be affected differentially [3, 34, 52, 55, 58]. This especially applies to assessments primarily developed for research purposes, which are often focused on the specific apraxic impairment under investigation. In contrast, apraxia assessments used for the daily clinical routine need to provide a high diagnostic sensitivity, which can usually only be achieved when many apraxic symptoms are concurrently assessed. Taking into account that apraxia is often accompanied by aphasia [17, 44], tests for clinical application should focus on test items that use objects or gestures rather than language as the trigger for actions because in patients with comorbid aphasia it is difficult to differentiate whether the motor deficits observed after verbal instructions are primarily due to the apraxic or aphasic (e.g., reduced language comprehension) impairment. Moreover, a tool used in a clinical environment to test for upper limb apraxia often necessitates a quick and easy application, and should hence require as few test items as possible. Finally, it is important that the psychometric properties of clinical apraxia tests are available with reliable cut-off values.

Accordingly, we performed a literature search to identify all tests developed for diagnosing upper limb apraxia that have been published so far. The literature search targeted the period from January 1965 until April 2011. The following keywords were entered into the medical search engine Medline (PubMed): "apraxia" AND "assessment" OR "test". In addition, the reference list of all relevant articles was reviewed for further references. Table 1 summarizes all apraxia assessments identified by means of the search. In particular, Table 1 provides information on the stimulus types used to trigger the actions and the involved processing routes (semantic, structural; see below). Table 1 also indicates whether cut-off values for an apraxic impairment are provided, and whether psychometric test properties have been assessed. Furthermore, details on the test duration, the required test material as well as on the population in which the test was initially validated are provided. Finally, it is indicated whether an item analysis or rather an item reduction was carried out, and whether, in addition to gestures of the upper limbs, bucco-facial gestures were also included in the test.

As a detailed description and evaluation of all published assessments would go beyond the scope of this article, we defined a priori criteria to select assessments for a more detailed appraisal: As described above, apraxic impairments affecting meaningless gestures as well as apraxic deficits related to meaningful gestures have both a negative impact on independently performing ADLs and on the outcome of (stroke) rehabilitation. According to previously described models of apraxia ${ }^{1}[14,23,55]$, these deficits represent impairments of the structural (for meaningless gestures) and the semantic (for meaningful gestures) processing route. Meaningful gestures that are recognized after initial processing are processed along the semantic route, which means that information about the gesture is retrieved from the so-called action semantic system, which enables the activation of all required movement elements as a whole, while processing along the structural route allows for activation of single movement elements only. This notion has-in part-been proposed by previous apraxia models [14, 55]. The structural route is based on visuomotor conversion mechanisms directly transferring the visual analyses into motor programs without assessing semantic information. Thus, disturbed processing in both the structural and the semantic processing routes affect ADL performance and neurorehabilitation in apraxic patients. Therefore, we considered it relevant that a clinical test assesses impairments of both the structural and the semantic processing route as otherwise patients with deficits leading to impairments of motor functions relevant for daily living might be overlooked. Moreover, for a diagnostic tool, we consider it indispensable that clear cut-off values are provided according to which the patient's test performance can be classified as either normal or impaired. Hence, only apraxia tests that comprise both items tapping the structural and the semantic route (i.e., including meaningless and meaningful items) and that also provide defined cut-off values will be described in more detail. Based on these criteria, eight assessments were selected

\footnotetext{
${ }^{1}$ Recently, an alternative model (the so-called Computation, Anatomy, and Physiology (CAP) Model) describing principles underlying upper-limb actions has been proposed by Frey and colleagues [27].
} 
Table 1 Summary of the published assessments developed for diagnosing upper limb apraxia (until April 2011; note that tests are ordered by publication year)

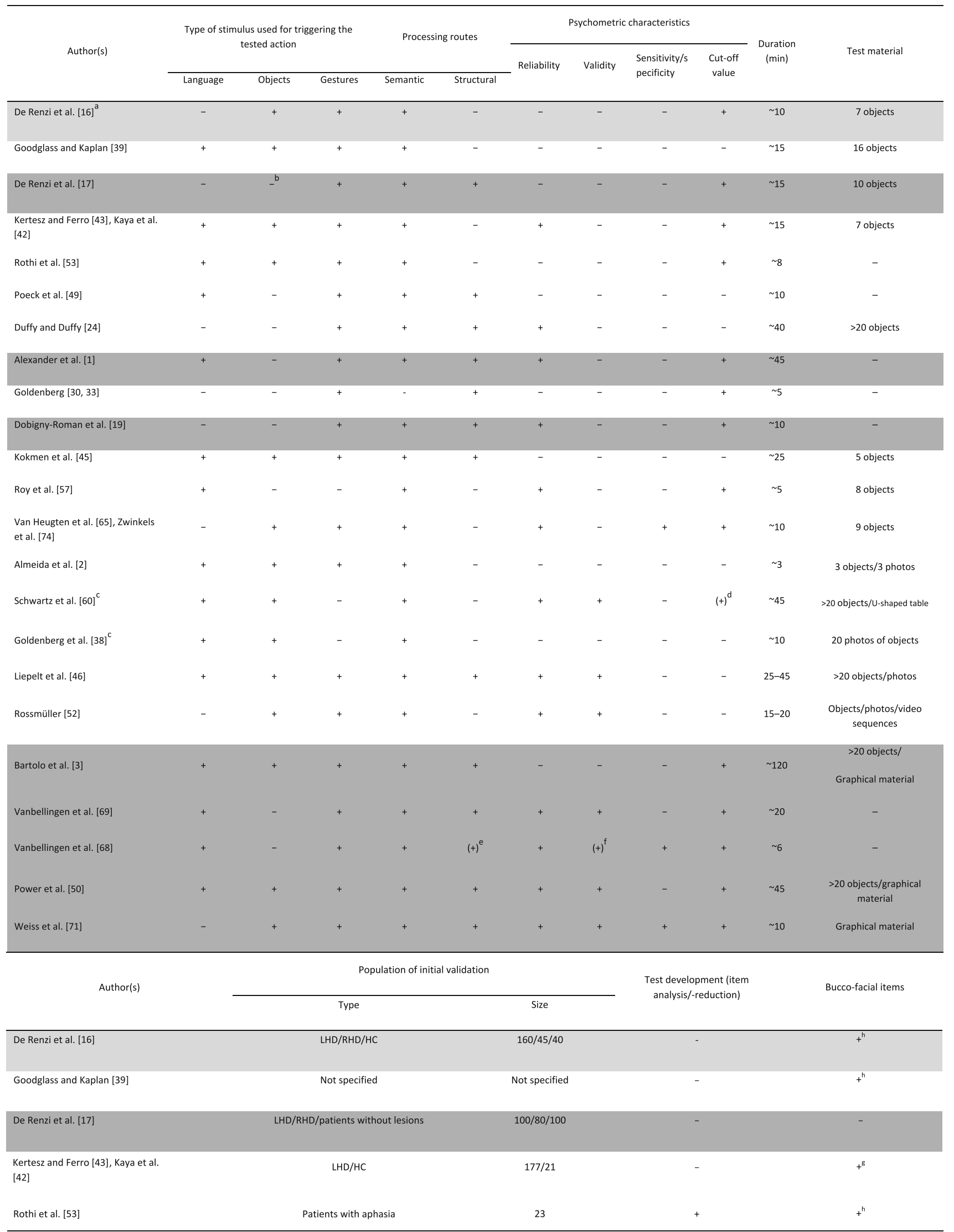


Table 1 contiuned

\begin{tabular}{|c|c|c|c|c|}
\hline \multirow{2}{*}{ Author(s) } & \multicolumn{2}{|c|}{ Population of initial validation } & \multirow{2}{*}{$\begin{array}{l}\text { Test development (item } \\
\text { analysis/-reduction) }\end{array}$} & \multirow{2}{*}{ Bucco-facial items } \\
\hline & Type & Size & & \\
\hline Poeck et al. [49] & - & - & + & $t^{h}$ \\
\hline Duffy and Duffy [24] & LHD/RHD/HC & $77 / 44 / 30$ & - & Not specified \\
\hline Alexander et al. [1] & LHD/RHD/HC & $55 / 18 / 23$ & - & $t^{\mathrm{g}}$ \\
\hline Goldenberg [30, 33] & LHD/RHD/HC & $80 / 40 / 60$ & - & - \\
\hline Dobigny-Roman et al. [19] & $\mathrm{AD} /$ cognitively healthy patients & $55 / 26$ & - & - \\
\hline Kokmen et al. [45] & $\mathrm{NDD} / \mathrm{HC}$ & $74 / 81$ & - & $t^{h}$ \\
\hline Roy et al. [57] & $\mathrm{LHD} / \mathrm{RHD} / \mathrm{HC}$ & $26 / 37 / 10$ & - & $t^{h}$ \\
\hline $\begin{array}{l}\text { Van Heugten et al. [65], Zwinkels et } \\
\text { al. [74] }\end{array}$ & $\begin{array}{l}\text { LHD with apraxia/LHD without } \\
\text { apraxia/HC }\end{array}$ & $44 / 35 / 50$ & - & $t^{h}$ \\
\hline Almeida et al. [2] & LHD or RHD/HC & $37 / 30$ & + & - \\
\hline Schwartz et al. [60] & LHD/RHD/TBI & $30 / 45 / 25$ & - & - \\
\hline Goldenberg et al. [38] & $\mathrm{LHD} / \mathrm{RHD} / \mathrm{HC}$ & $40 / 12 / 20$ & - & $+^{h}$ \\
\hline Liepelt et al. [46] & LHD/RHD/AD & $40 / 20 / 12$ & + & $t^{h}$ \\
\hline Rossmüller [52] & $\begin{array}{l}\text { LHD/geriatric patients without } \\
\text { neurological diagnosis }\end{array}$ & $35 / 35$ & + & - \\
\hline Bartolo et al. [3] & $\mathrm{HC}$ & 60 & + & $t^{n}$ \\
\hline Vanbellingen et al. [69] & LHD/RHD/HC & $84 / 49 / 50$ & - & $t^{h}$ \\
\hline Vanbellingen et al. [68] & LHD/RHD & $26 / 5$ & + & $t^{h}$ \\
\hline Power et al. [50] & HC & 16 & - & $t^{h}$ \\
\hline Weiss et al. [71] & $\mathrm{LHD} / \mathrm{HC}$ & $58 / 50$ & + & $t^{h}$ \\
\hline
\end{tabular}

Lines highlighted in dark grey indicate apraxia tests that are described in more detail in the text, as these tests fulfill our predefined selection criteria (i.e., provide cut-off scores and assess both the structural and the semantic processing route)

Examined patient populations according to the categorization by the authors: $L H D$ left hemisphere damage, $R H D$ right hemisphere damage, $H C$ healthy controls, TBI traumatic brain injury, $A D$ Alzheimer's disease, $N D D$ neurodegenerative diseases (e.g. Alzheimer's disease, Parkinson's disease, etc.)

${ }^{a}$ The apraxia test by De Renzi et al. ([16], marked with light grey) does not comply with the above-described selection criteria, but is nevertheless discussed within the text because-in contrast to the assessments fulfilling the predefined selection criteria (marked with dark grey) — this test contains a subtest for the assessment of actual object use

b De Renzi et al. [17] also examined pantomime of object use (on visual presentation of the objects). However, this subtest was not applied to all patients and controls and was not relevant for the determination of the cut-off scores indicating apraxic impairment

c In the assessments by Schwartz et al. [60] and Goldenberg et al. [38], "language" and "objects" are not separately used to trigger the tested action, but are used concurrently

${ }^{\mathrm{d}}$ Schwartz et al. [60] describe in detail how to administer and score single subtests, however, a clear cut-off score for an apraxic impairment is missing. Nevertheless, as the performance of different patient groups (patients with left- or right-hemisphere stroke, patients with traumatic brain injury), and the performance of a healthy control group is reported, it is possible to relate a given test score to the scores achieved by the different patient groups and controls

e Please note that the apraxia screening (AST) by Vanbellingen et al. [68, 69] contains only one item to test for deficits of the structural processing route

${ }^{\mathrm{f}}$ Validity of the AST was only assessed with respect to the TULIA (a more comprehensive apraxia test, based on which the AST was built by means of item reduction). Analysis of the validity with respect to an external criterion has not been assessed so far

$\mathrm{g}$ The assessment contains a subtest for the acquisition of bucco-facial apraxia (including a separate cut-off value)

h The assessment contains one or more bucco-facial items but not a separate cut-off for the diagnosis of bucco-facial apraxia 
(see lines highlighted in dark grey in Table 1). Note that one of these assessments was not primarily developed for assessing upper limb apraxia but for diagnosing Alzheimer's disease, where upper limb apraxia represents one of the early symptoms due to atrophy of the parieto-temporal cortex [19]. Accordingly, in a population of healthy elderly people and patients with Alzheimer's disease, the cut-off value of this test was chosen in a way to ensure that patients with Alzheimer's disease were identified as reliably as possible (high sensitivity) and that the healthy elderly people without cognitive impairments should be reliably classified as not suffering from Alzheimer's disease (high specificity). Importantly, this test was not applied to patients with (left-hemisphere) stroke.

The remaining seven tests, which examine both the structural and semantic processing routes and report cut-off values, were explicitly developed as diagnostic tools for detecting upper limb apraxia in stroke patients and thus will be discussed in detail. For clarity, we differentiate between short screening tests for symptoms of apraxia, tests for a clinical diagnosis of apraxia, and comprehensive test batteries, which might be used for scientific purposes, but which are too time-consuming for every-day clinical routine.

\section{Short screening tests for upper limb apraxia}

Two short apraxia screenings $[68,71]$ which are accomplishable at the bedside fulfilled the selection criteria described above.

\section{Apraxia screen of TULIA (AST)}

The AST (Apraxia screen of TULIA) by Vanbellingen et al. [68] is based on a more comprehensive test procedure of the same study group (Test for Upper-Limb Apraxia, TULIA; see below) and was constructed via an item reduction of the original test procedure. By means of item reduction, the test was shortened from originally 48 to 12 items. A high specificity (93\%) as well as a high sensitivity $(88 \%)$ was achieved with the cut-off-values determined by the authors. A highly significant correlation between AST and TULIA scores points towards a good validity of the screening test; a validation with an external (i.e., an independent) assessment is not yet provided, but would be desirable. Furthermore, the high correlation between the scores of the 12 AST items and the partial scores when the same 12 items are tested within the framework of the TULIA indicates a good test-retest reliability of the AST. However, it should be critically noted that after item reduction there was just one item left in the AST tapping the structural pathway.
Cologne apraxia screening (CAS)

The CAS is an apraxia screening that was developed to create a sensitive, reliable, and valid screening tool for clinical purposes [71]. The CAS requires patients to pantomime the use of objects (i.e., transitive gestures) as well as to imitate abstract and symbolic (intransitive) gestures. Pantomime of object use is tested by presenting the patient (black-and-white) photos of objects whose handling the patient should pantomime. Objects are always displayed in a way that suggests the usage of the left hand, i.e., the nonparetic hand for patients with left-hemisphere stroke. Using photographs reduces the required verbal instructions and assures a standardized test application. In contrast to many other assessments, Weiss and colleagues also use photographs in the imitation tasks thereby removing stimulus differences that inevitably occur when gestures are demonstrated by different examiners. The CAS assesses impairments of the structural as well as the semantic pathway and takes two out of three possible input modalities into account (objects and gestures). Weiss and colleagues purposely refrained from using verbal instructions (language) as an input modality as motor deficits for verbally instructed test items may result from the often co-morbid aphasia.

In comparison to many other apraxia assessments, an important advantage of the CAS is that an item reduction was performed: based on the performance of a sample of 30 neurological patients and 19 healthy control subjects, those test items were selected that discriminated best the performance of the two groups. Due to a subsequent item reduction, the CAS was then confined to 20 items and can hence be administered within approximately $10 \mathrm{~min}$. The inter-rater reliability is high. In addition, the construct validity, which was assessed using the test for imitating hand postures and finger configurations by Goldenberg [30] as external criterion, is also high. Especially the correlation between the CAS scores and the scores of the hand imitation test, which is known to be sensitive in detecting apraxic deficits, was very good. Moreover, the CAS has a high sensitivity and specificity.

Assessments for the clinical diagnosis of upper limb apraxia

\section{Apraxia test by De Renzi et al. [17]}

Thirty years ago, a test for upper limb apraxia assessing both processing routes and providing cut-off-values was published by De Renzi et al. [17]. This test is solely comprised of imitation tasks. The gestures that have to be imitated are each classifiable according to three dimensions: (1) the gesture requires either independent 
movements of the fingers or a movement of the whole hand, (2) the gesture is merely a static posture or a motor sequence, (3) the gesture is either meaningful or meaningless. The combinations of these three dimensions result in eight categories, which are represented by three items per category. Gestures are presented to the patient up to three times, but fewer points are given when the gesture is not immediately imitated correctly. As the administration of the whole test requires approximately $15 \mathrm{~min}$ and as no test material is required, this test can be used at the bedside. De Renzi and colleagues applied the test to 100 patients without brain damage, 80 patients with right hemisphere damage, and 100 patients with left hemisphere damage. A cut-off value was determined based on the performance of the patients without brain damage. The main disadvantage of this test procedure is that no psychometric properties have been determined. However, information on reliability and validity as well as information on specificity and sensitivity is of great importance for tests to be used for clinical diagnoses.

\section{Test of upper limb apraxia (TULIA)}

Recently, Vanbellingen and colleagues [69] developed a test battery for the assessment of upper limb apraxia (TULIA) that comprised tasks requiring the production of abstract as well as symbolic gestures, thereby testing both the structural and the symbolic route. Moreover, the test allows for testing both transitive and intransitive symbolic gestures. All gestures have to be produced after the examiner demonstrates them in a mirrored fashion (imitation) and after verbal request. Hence, two out of three possible input modalities (gestures, language) are tested by the TULIA. All gestures require the use of one hand only and can be performed by the patient with his non-paretic hand. In total, this test procedure contains 48 items that can be accomplished in roughly $20 \mathrm{~min}$. Validation of the TULIA was carried out in a sample of 133 stroke patients (84 with left-hemisphere and 49 with right-hemisphere stroke) and 50 healthy control subjects. Based on this sample, a cut-off value was determined according to which apraxia is diagnosed if a patient scores two standard deviations below the mean of healthy control subjects. Both inter-rater and retest reliability were calculated. Most items showed a (very) good ( $\kappa 0.65-0.99)$, and only few items $(n=6)$ a moderate $(\kappa 0.35-0.50)$ inter-rater reliability. Likewise, the retest reliability (assessed by testing 20 patients three times within $24 \mathrm{~h}$ ) was very high for nearly all subtests (Cronbach's alpha $>0.83$ ); merely the subtest for imitation of meaningless gestures had a slightly lower Cronbach's alpha (0.67). Vanbellingen and colleagues also provide information on the criterion and construct validity. The criterion validity describes the relationship between the results of the diagnostic tool and an empirical criterion. The external criterion chosen by Vanbellingen and colleagues was the clinical observation that impairments of gesture production occur more frequently after left-hemisphere than after right-hemisphere stroke [30, 74]. As the TULIA clearly classified more left than right hemisphere damaged patients as apraxic (68 vs. $39 \%$ ) and as in the majority of cases apraxia severity was more pronounced in patients with left-hemisphere stroke, good criterion validity of the TULIA was assumed. A good construct validity of a test is given, if either the test scores correlate high with the scores of an instrument measuring the same construct (convergent validity), or correlate low with scores of a test measuring a different construct (discriminate validity). In order to assess the convergent validity of the TULIA, a subgroup of the patients (21 patients with left-hemisphere and 12 with right-hemisphere stroke) was additionally tested with the test for apraxia by De Renzi and colleagues [17]. A high correlation $(r=0.82)$ between the scores of the two test procedures points to a good convergent validity. In contrast, sensitivity and specificity were not assessed as the authors argued that there is no suitable instrument that could be used as an external criterion. Altogether, the test procedure by Vanbellingen and colleagues constitutes a reliable and valid instrument for the assessment of upper limb apraxia.

\section{Apraxia test by De Renzi and colleagues [16]}

Although the apraxia tests and screenings introduced above all fulfill our selection criteria, none of these includes an assessment of actual object use. However, as the clinical situation (or the scientific study) may demand a quantitative assessment of actual object use, we here describe a further test by De Renzi and colleagues [16] that contains a subtest for assessing how patients actually use objects, although this test does not fulfill the a priori selection criteria. In addition to the subtest of actual object use, this test contains a subtest for the imitation of intransitive meaningful gestures. For the assessment of actual object use, patients are consecutively given seven objects (hammer, toothbrush, pair of scissors, revolver, pencil eraser, lock and its key, and a candle together with a matchbox) and the patient is asked to actually use each of the seven objects (see also [22]). For the second subtest, the patient is required to imitate ten intransitive, meaningful gestures demonstrated by the examiner (e.g., waving goodbye). Based on the examination of 40 patients without brain damage and 205 patients with brain damage (45 with righthemisphere lesions, 160 with left-hemisphere lesions) cutoff values for both subtests were determined. As the authors determined a separate cut-off value for the object use subtest, the test may allow the detection of (isolated) 
object use deficits. However, other psychometric properties were not assessed. Nonetheless, the object use subtest can be used in addition to one of the better validated diagnostic apraxia tests described in "Short screening tests for upper limb apraxia" and "Assessments for the clinical diagnosis of upper limb apraxia" (e.g., CAS, TULIA) as these tests do not assess actual object use.

Apraxia tests primarily applicable for scientific purposes

\section{Apraxia test by Alexander and colleagues [1]}

Alexander and colleagues [1] conceived a test for the assessment of apraxia in a study designed to examine the relationship of different motor impairments with lesion size and localization as well as with different forms of aphasia. The apraxia test developed by Alexander et al. [1] comprises four subtests testing different body parts (buccofacial, axial, upper limb, and respiratory movements), which all include both meaningful and meaningless items, thus assessing deficits of both the semantic as well as the structural processing route. Based on the test performance of 23 healthy control subjects, the inter-rater reliability and cut-off values were determined, but no further psychometric properties (e.g., validity, specificity, and sensitivity) were reported. The apraxia test by Alexander and colleagues is exemplary for many tests for which no complete psychometric analyses have been conducted [30, 31, 57] as they were developed for scientific purposes.

\section{Test battery by Bartolo and colleagues [4]}

In the following two comprehensive test batteries for the assessment of upper limb apraxia will be described [4, 50]. Both test batteries are based on a cognitive model of limb apraxia originally devised by Rothi and colleagues $[55,56]$ or a slight modification thereof by Cublli and colleagues [14]. The aim of the comprehensive test battery by Bartolo et al. [4] is to assess as many aspects as possible of their apraxia model. To examine the semantic pathway (here called lexical route), the following tasks were proposed by the authors: production of intransitive, meaningful gestures, pantomime of object use, and actual use of single objects (note that no items for the assessment of complex object use were included). Furthermore, the semantic pathway was tested via different input modalities. That is, intransitive, meaningful gestures were executed either after verbal command or after visual presentation of pictures on which different scenes were displayed prompting for a specific gesture. In addition, intransitive meaningful gestures have to be imitated by the patient after they had been demonstrated by the examiner. Also, pantomime of object use (transitive gestures) is tested via different input modalities, namely either after verbal command, after visual presentation of the object, or after recognizing the object via tactile exploration. Finally, also transitive gestures are tested by means of an imitation task. Impairments of the structural (here: non-lexical) pathway are assessed with the help of tasks requiring the imitation of meaningless gestures. This test battery specifically contains tasks in which the recognition and comprehension of symbolic gestures are assessed without the requirement of actually producing these gestures. This subtest is motivated by the fact that the cognitive model of apraxia by Cubelli et al. [14] allows for a dissociation between gesture production and gesture comprehension. In fact, such a dissociation (intact imitation but impaired recognition of meaningful gestures) has previously been described in patients with left-hemisphere brain damage [54]. Overall, this extensive test battery by Bartolo and colleagues [4] contains 13 different kinds of tasks with each comprising at least 20 items. As a result of the huge amount of test items, the administration of this test battery takes about $2 \mathrm{~h}$ already in healthy subjects and requires an extensive amount of test material. Cut-off values indicating an apraxic impairment were determined based on the means and standard deviation of 60 healthy control subjects (mean -3 , standard deviations -1 ). For subtests on which healthy subjects did not make any mistakes at all (mean equates to maximal score, standard deviation equates to zero), the cut-off value was defined as the maximal subtest score minus one. However, these cut-off values have to be called into question, as the test battery has not yet been applied to an adequate patient sample. For the same reason, no details can be provided about specificity and sensitivity as well as reliability and validity of this apraxia test battery.

\section{Florida apraxia battery-extended and revised Sydney (FABERS)}

A second comprehensive test battery for the assessment of upper limb apraxia (FABERS) was published recently by Power and colleagues [50]. Their test battery was based on the cognitive model of apraxia by Rothi and colleagues $[55,56]$. Like the test battery by Bartolo and colleagues, this apraxia test also contains tasks for the assessment of both the semantic and the structural pathway. Tasks requiring the production of transitive and intransitive but meaningful gestures are adopted to test the semantic pathway. Again, different input modalities are used to prompt the gesture production (language: verbal instruction for transitive (i.e., pantomime) and intransitive, meaningful gestures; objects: visual presentation of objects triggering transitive gestures; gestures: imitation of transitive and intransitive gestures). Similarly, Power and colleagues used 
tasks that require the imitation of meaningless gestures and motor sequences to detect possible impairments of the structural pathway. In contrast to the test battery by Bartolo and colleagues, the test battery by Power and colleagues does not contain any items assessing the actual use of objects.

In addition to the tasks assessing gesture production, this apraxia test battery also contains tasks to examine the comprehension of meaningful gestures. Administration of the whole test procedure is estimated to take about $45 \mathrm{~min}$. Based on the data of a sample of 16 healthy elderly control subjects, the inter-rater reliability of the different subtests was shown to be high $(\geq 89 \%)$. Moreover, a cut-off value indicating impairment was determined based on the performance of these 16 healthy elderly controls (values below the 10th percentile of the 16 subjects indicate an impairment). However, the test battery has not yet been applied to stroke patients and thus specificity and sensitivity of the test procedure are unknown.

\section{Treatment of upper limb apraxia}

Up to now, only a few studies have been published that investigated the efficacy of treatments for upper limb apraxia. This might be, at least in part, due to the widely held but erroneous assumption that apraxia shows up during neuropsychological testing only but does not cause a significant impairment in daily life (voluntary-automatic dissociation [5]). Contrary to this assumption, it has been demonstrated that apraxia significantly affects patients in their everyday lives and has a negative impact on their rehabilitation [6, 26, 29, 35, 40, 63].

An extensive literature search (including the period from January 1965 to April 2011) in Medline (PubMed) using the keywords 'apraxia' AND 'rehabilitation' OR 'treatment' OR 'therapy' was conducted. In addition, the reference lists of the articles identified by means of the literature search were screened for further relevant articles. Altogether, this procedure revealed three studies that investigated rehabilitation strategies of upper limb apraxia by means of randomized controlled trials (RCTs [21, 61, 62]). Beyond that, only a few randomized, explorative studies $[35,37,64]$ as well as several single case studies have been published [9, 10]. The results of these latter studies do not, however, meet the requirements of current evidence-based approaches. Nevertheless, they can provide interesting suggestions for the development of novel treatment strategies. When evaluating the quality of a given treatment, it is of great importance whether the positive effect of the treatment persists after the treatment has been terminated. Furthermore, it should be assessed whether a transfer of positive treatment effects takes place (i.e., from trained to untrained activities, from the training environment into another environment).

Table 2 provides an overview of all group studies investigating treatment strategies for apraxia that have been published so far. In the following, the gesture training [61, 62] as well as the strategy training [21] will be described in detail as both approaches have been examined by RCTs. Finally, two additional therapeutic approaches, namely the explorative and the direct training by Goldenberg and colleagues [35, 37], will be detailed, which might provide the reader with suggestions for additional therapeutic interventions, even so the evidence supporting these therapeutic approaches is insufficient at the moment. The direct training, in which the patient is taught to routinely retrieve the trained movements when they are required in daily life, belongs to the so-called 'bottom-up' approach, while the strategy training, the gesture training, and explorative training are assigned to the 'top-down' approach, in which general principles of object use are learned throughout a training period, which subsequently can be applied not only to trained but also to untrained activities [51].

\section{Gesture training}

Smania and coworkers [61] were the first who published a study in which they investigated the effect of a therapeutic intervention on the rehabilitation of apraxia in an RCT. This study can be considered a proof-of-principle-study as only 13 patients were included. Afterwards, the effectiveness of the therapeutic intervention was tested in a larger, randomized controlled study with 45 apraxic patients [62]. In both studies, a specific intervention for the rehabilitation of apraxia was compared to a conventional therapy for aphasia. In the first study, both the control group $(n=7)$ and the experimental group $(n=6)$ received 35 training sessions each lasting $50 \mathrm{~min}$. The experimental apraxia training included tasks with regard to three different domains of gesture production: transitive gestures, intransitive meaningful gestures, and intransitive meaningless gestures. Two of the tasks were presented with three different degrees of difficulty, always starting with the easiest alternative. Subsequently, the tasks were complicated by taking away (the therapist's) support, in a stepwise fashion. That is, during the first phase of the training for transitive gestures, objects were handed over to the patients who were asked to appropriately use the respective objects (actual object use, phase A). During the next phase, pictures were shown to the patients, which displayed the usage of objects in an appropriate context (e.g., a person, raising a spoon to his/her mouth while eating soup). In the following, the patients were asked to imitate the object use as shown on the picture (phase B). Finally, during the most 
Table 2 Summary of all published group studies examining the efficacy of therapeutic interventions for apraxia (until April 2011; note that studies are ordered by publication year)

\begin{tabular}{|c|c|c|c|c|c|c|c|c|}
\hline Authors & $\begin{array}{c}\text { Number } \\
\text { of } \\
\text { patients }\end{array}$ & Study design & $\begin{array}{l}\text { Therapeutic } \\
\text { intervention }\end{array}$ & $\begin{array}{l}\text { Duration of the } \\
\text { intervention }\end{array}$ & $\begin{array}{c}\text { Outcome/dependent } \\
\text { variables }\end{array}$ & $\begin{array}{l}\text { Positive } \\
\text { effect }\end{array}$ & $\begin{array}{l}\text { Follow-up } \\
\text { examination }\end{array}$ & Transfer $^{\mathrm{a}}$ \\
\hline $\begin{array}{l}\text { Goldenberg and } \\
\text { Hagmann [35] }\end{array}$ & 15 & $\begin{array}{c}\text { Pre/post test } \\
\text { design }\end{array}$ & $\begin{array}{c}\text { Direct } \\
\text { training + explorative } \\
\text { training }\end{array}$ & $\begin{array}{l}5 \times 20-40 \text { min/week; } \\
1 \mathrm{ADL} / \text { week; } \\
\text { (until no major errors } \\
\text { occurred) }\end{array}$ & 3 ADLs & + & $\begin{array}{c}\text { Positive } \\
\text { treatment effect } \\
\text { after } 6 \text { months }\end{array}$ & - \\
\hline $\begin{array}{l}\text { Van Heugten } \\
\text { et al. [66] }\end{array}$ & 33 & $\begin{array}{c}\text { Pre/post test } \\
\text { design }\end{array}$ & Strategy-training & $\begin{array}{c}3-5 \times 30 \mathrm{~min} / \text { week; } \\
12 \text { weeks }\end{array}$ & $\begin{array}{l}\text { Apraxia tests (De Renzi } \\
{[16,17] \text { - modified); }} \\
\text { ADL observations; } \\
\text { Barthel Index } \\
\text { ADL questionnaire }\end{array}$ & + & n.a. & $t^{c}$ \\
\hline
\end{tabular}

\begin{tabular}{|c|c|c|c|c|c|c|c|c|}
\hline Smania et al. [61] & 13 & $\begin{array}{l}\text { Randomised } \\
\text { controlled } \\
\text { trial (RCT) }\end{array}$ & $\begin{array}{l}\text { Gesture training vs. } \\
\text { conventional therapy } \\
\text { for aphasia }\end{array}$ & $\begin{array}{c}3 \times 50 \mathrm{~min} / \text { week; } \\
35 \text { sessions }\end{array}$ & $\begin{array}{c}\text { Apraxia tests (De Renzi et } \\
\text { al. }[16,17]) ; \\
\text { Gesture recognition }\end{array}$ & + & n.a. & $+^{c}$ \\
\hline $\begin{array}{l}\text { Donkervoort } \\
\text { etal. [21] }\end{array}$ & 139 & $\begin{array}{l}\text { Randomised } \\
\text { controlled } \\
\text { trial (RCT) }\end{array}$ & $\begin{array}{l}\text { Occupational } \\
\text { therapie + strategy- } \\
\text { training vs. } \\
\text { occupational therapy }\end{array}$ & $\begin{array}{l}8 \text { weeks; } \\
\text { number and duration of } \\
\text { treatment sessions is } \\
\text { not further specified }\end{array}$ & $\begin{array}{l}\text { ADL observations; } \\
\text { Barthel ADL Index; } \\
\text { ADL judgement by } 1 . \\
\text { therapist and 2. patient }\end{array}$ & + & $\begin{array}{l}\text { Absence of } \\
\text { therapeutic } \\
\text { effect after } 5 \\
\text { months }\end{array}$ & $t^{d}$ \\
\hline $\begin{array}{l}\text { Goldenberg et al. } \\
\text { [37] }\end{array}$ & 6 & $\begin{array}{l}\text { Comparison } \\
\text { of } 2 \\
\text { interventions } \\
\text { in a within- } \\
\text { subject } \\
\text { design }\end{array}$ & $\begin{array}{l}\text { direct training (DT) } \\
\text { vs. explorative } \\
\text { training (ET) }\end{array}$ & $\begin{array}{l}\text { For each intervention: } \\
\begin{array}{l}2 \times 2 \text { weeks with } 6 \\
\text { sessions of } 60 \text { min per } \\
\text { week }\end{array}\end{array}$ & $4 \mathrm{ADLs}$ & $\begin{array}{l}+(\mathrm{DT}) \\
-(\mathrm{ET})\end{array}$ & $\begin{array}{l}\text { Positive } \\
\text { treatment effect } \\
\text { after } 3 \text { months } \\
\text { (DT) }\end{array}$ & ${ }_{-}^{\mathrm{e}}$ \\
\hline
\end{tabular}

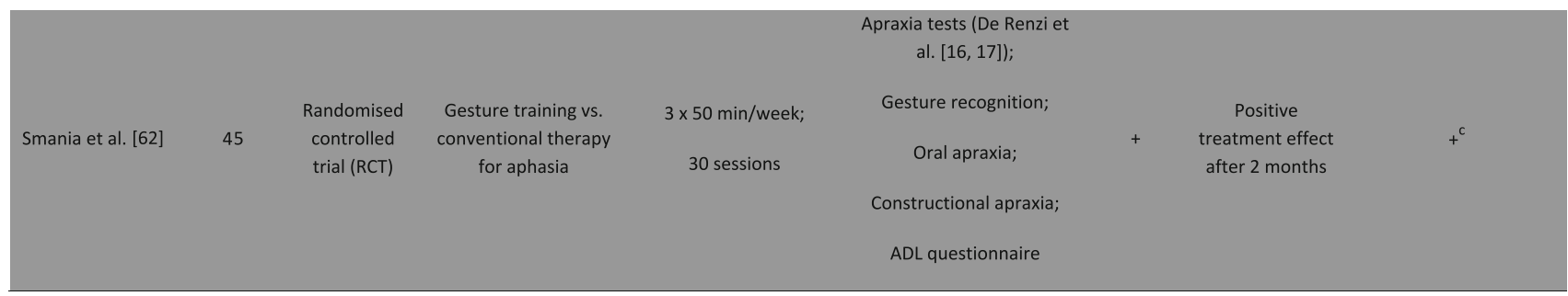

Randomized controlled trials (RCTs) are highlighted in grey

${ }^{a}$ Entries in this column indicate whether the positive treatment effect was transferred to other tasks, objects, or environments

b During the follow-up examination, only patients who continued ADL training at home showed a positive treatment effect

c As patients improved on ADL measures and/or Barthel Index, it can be assumed that the positive treatment effect occurred not only for the specifically trained tasks but that a transfer to other tasks took place

d Based on a reanalysis of the data by Donkervoort et al. [21], Geusgens and colleagues (2006) found indications for a transfer of the positive treatment effects of the strategy training to untrained tasks [28]

e At the end of the treatment, Goldenberg et al. [37] tested the same activities with a different set of objects and reported increased error rates when compared to the test with the objects used during the training sessions. Thus, the treatment effect of the direct training is very specific and cannot be transferred to a novel environment, i.e., a different set of objects

difficult phase, pictures merely showing the object were presented. Patients were asked to pantomime the use of these objects (phase $\mathrm{C}$ ). Likewise, the training of the intransitive, meaningful gestures was divided into three phases. During the first phase, two pictures were shown to the patients. While one of the pictures illustrated a specific scene (context picture), the second picture showed a symbolic gesture fitting into this context. Patients were required to imitate this gesture (phase A). During the next phase, only the context picture was shown to the patient who was required to recall which gesture would be appropriate in the shown context and then to demonstrate this gesture (phase B). For the last phase (phase C), again pictures showing contexts were used to test for intransitive, 
meaningful gestures. These context pictures were new, but related to the previous contexts, thus triggering the same gestures and thereby assessing whether a transfer of the gestures occurred that had been learned in phases A and B. In both the training of the transitive gestures and training of the intransitive gestures, each phase contained 20 items. Once a patient correctly performed 17 out of 20 items, the training of the next phase commenced. Finally, intransitive meaningless gestures were practiced during the last part of the gesture training. Here, patients had to imitate meaningless gestures demonstrated by the therapist. The therapist noted whether a gesture was imitated correctly without any support or only after the therapist provided verbal or other support.

Effectiveness of the therapeutic intervention was examined by applying the following tests before the first training session as well as after the last training session: a test for real object use [16], a test for the imitation of meaningful as well as meaningless intransitive gestures [17], and a test assessing recognition of transitive and intransitive gestures developed by Smania and coworkers. The experimental group improved significantly on the tests for real object use and imitation of intransitive gestures. Furthermore, an improvement in the gesture recognition task was observed, which however was not significant. In contrast, patients of the control group who did receive conventional aphasia therapy, did not show an improvement in any of the tests. Although Smania and colleagues did not report significant results for the direct group comparison, they demonstrated for the first time that therapeutic intervention for apraxia might have a positive effect.

Based on these positive results, Smania and colleagues [62] performed a second study on the effectiveness of their gesture training in a larger sample of 45 patients with left hemispheric stroke and apraxia. The main focus of the second study was to investigate the clinical relevance of the previous results. That is, with the help of an additional ADL questionnaire, the authors examined whether gesture training also improved ADLs or whether the improvements by the gesture training were restricted to the neuropsychological assessment. In this study, the improvement after therapy has directly been tested between groups and turned out to be significant not only for apraxia scores but also for the ADL questionnaire, implying that they performed ADLs more independently after the training. Finally, follow-up measurements in a subgroup of 17 patients (nine patients from the experimental group) after 2 months, revealed a lasting positive effect (on ADL questionnaire and tests for apraxia) of the gesture training. Taken together, the two studies by Smania and colleagues provide indications for the efficacy of their gesture training. However, it should be noted that the sample sizes of the two studies ( $n=13$ and $n=45$ ) are relatively small in comparison to the study by
Donkervoort and colleagues who evaluated their strategy training in 139 apraxic patients (see "Strategy training").

\section{Strategy training}

In a further RCT, Donkervoort and colleagues [21] evaluated the strategy training previously developed by van Heugten and colleagues [64]. The initial study, which investigated the efficacy of the strategy training, was based on a pre-post test design, but lacked a control group and thereby did not fulfill the requirements of an RCT. Van Heugten and colleagues [64] had shown by means of an explorative study that patients showed significant improvements in ADLs after a 12-week treatment with a strategy training, but no improvement in apraxia (as assessed by different neuropsychological tests).

As these results suggest that the strategy training might be effective in helping subjects to perform more independently in daily life despite persistent apraxia, Donkervoort and colleagues examined the efficacy of this training in an RCT [21]. Assuming that apraxia is a persistent and difficult-to-treat syndrome, this therapeutic approach is aimed at teaching patients strategies that might help to compensate for apraxic deficits in daily life. One hundred and thirty-nine patients suffering from left-hemisphere stroke (dating back 4 weeks to 2 years) and apraxia were randomly assigned to either the control or the experimental group. While the control group received a standardized occupational therapy, the experimental group received additional strategy training within the framework of the occupational therapy. During strategy training, the patient practiced several ADLs with support by an occupational therapist. Dependent on the patient's degree of impairment, the occupational therapist supported the patient at three different stages according to a detailed protocol [64]. That is, if a patient is primarily impaired in initiating an action, the occupational therapist can assist the patient by providing additional verbal instructions. If the patient still does not initiate the action, the occupational therapist might hand over the required objects to the patient. If on the other hand a patient has difficulties with the actual execution of an action, the occupational therapist can verbally describe the single steps needed for execution of the action or can provide direct physical support by, for example, correctly positioning the patients' limbs. Finally, the occupational therapist can provide feedback to the patient regarding the outcome of his/her action and/or could ask the patient to monitor the result of the action his/ herself. Before and after the 8-week therapy and also on a follow-up measurement 5 months later, ADL competences were assessed by means of an observation protocol [66, 67]. Furthermore, the Barthel index [70], the severity of apraxia (test for apraxia by van Heugten et al. [65]), and 
basic motor functions (Motricity Index [18], modified version of the Action Research Arm Tests [47]) were assessed in all patients at these three points in time. Patients who had received the strategy training showed a significant improvement in the ADL observation protocol and the Barthel index after 8 weeks of therapy compared to those patients who received the conventional occupational therapy only. No differences were found for any other parameters. At the follow-up measurement (i.e., after 5 months) no differences between the two different treatment groups could be detected.

\section{Direct training and explorative training}

Two more therapeutic approaches for the treatment of apraxia were proposed by Goldenberg and colleagues [35, 37]. One is called "direct training", in which the patient executes different ADLs with the aim to minimize errors with the help of an occupational therapist. Support of the occupational therapist is only reduced if the patient has gained more confidence when executing a given action. Furthermore, during direct training difficult passages of an action can repeatedly be trained, but the action should subsequently always be completed.

The second therapeutic approach, invented by Goldenberg and colleagues, is the so-called "explorative training", which aims at teaching patients to recognize the function of an object by analyzing its form and structure. In contrast to the direct training, the objects are not actually used throughout the explorative training, that is, the respective object-related actions are not executed. The ability to infer the function of an object from its structure is part of mechanical problem solving and enables the use of new, unknown objects [36]. Patients with left hemisphere damage compared to control subjects show difficulties when they need to infer functions of unknown tools [36]. According to Goldenberg and colleagues, this deficit may also contribute to difficulties of apraxic patients when using known objects. Accordingly, it was assumed that apraxic patients might improve in actual object use with the help of an explorative training.

Initially, Goldenberg and Hagmann [35] investigated in a study with apraxic patients ( $n=15$, no control group) the efficacy of a treatment consisting of both direct and explorative training. This study revealed a significant performance improvement in trained ADLs. However, a transfer to untrained ADLs could not be observed. Another problem concerns the results of the follow-up measurement carried out 6 months after the treatment sessions had been completed: only three out of six patients who were re-examined at follow-up showed a persistent therapy effect. Moreover, these patients reported that subsequent to therapy they continued training of the ADLs at home.
In a follow-up study, Goldenberg et al. [37] directly compared the direct training with the explorative training within a single patient group $(n=6)$. The explorative training did not lead to a significant improvement of ADL performance. In contrast, the direct training revealed a positive therapy effect: patients made less major errors and needed less support when executing the tested ADLs. This positive therapy effect of the direct training was also observed at the follow-up measurement 3 months later. However, it should be noted that the therapeutic success was restricted to the trained ADLs, i.e., it could not be transferred to untrained ADLs. Nevertheless, the direct training can be regarded as a promising approach to treat upper limb apraxia.

Besides the therapeutic approaches described in detail above, several other approaches have been proposed, which, however, were merely examined in single case studies (for an overview see $[9,10]$ ). Also interesting, but beyond the scope of this article, are treatment approaches that have been put forward to improve gestural performance in aphasic patients. Most of theses studies lack systematic evaluations of the treatment interventions [11, $12]$ or were only single-case studies $[11,13]$. However, one study recently proved the efficacy of an intervention to improve gestural expression in aphasia in a larger patient sample [15], indicating that it might be worth investigating its effects also in apraxic patients.

\section{Recommendations}

Recommendations for diagnosing upper limb apraxia

With respect to apraxia tests for scientific studies, neither of the two apraxia test batteries based on cognitive models of apraxia (see part "Apraxia tests primarily applicable for scientific purposes") can currently be recommended as the application of both test batteries to patients has not yet been documented $[4,50]$. Further shortcomings of these test batteries are that they either do not contain any item for actual object use [50] or that their psychometric properties such as reliability or validity have not been assessed [4].

For the application in the daily clinical routine, the Cologne apraxia screening (CAS) constitutes a reliable and valid screening tool. Due to the item reduction that was carried out during preparation of the CAS, the CAS can be accomplished at the bed side within approximately $10 \mathrm{~min}$. Moreover, given a comparable sensitivity and specificity of the CAS and the AST, we suggest using the CAS as the CAS comprises meaningful and meaningless gestures (i.e., testing both the semantic and the structural pathway), while the AST contains only one meaningless item and thus 
might overlook patients suffering from deficits that result from an impaired structural pathway.

For the purpose of a comprehensive clinical diagnosis, we suggest to use the TULIA [69], as it constitutes a reliable and valid comprehensive assessment for upper limb apraxia. Furthermore, no specific test material is needed, so that the test procedure can be easily accomplished at the bed side.

As both the CAS and the TULIA do not contain a subtest for actual object use, we recommend using the subtest for actual object use proposed by De Renzi et al. [16] if an impairment of object use is suspected. However, when using this test, it should be noted that no psychometric values for this test have been provided.

\section{Recommendations for treating upper limb apraxia}

To date, only a few (randomized, controlled) studies have been conducted to investigate the efficacy of different treatments for limb apraxia [10, 73]. Indeed, a review article of limb apraxia treatment after stroke is provided by the Cochrane library. However, based on the scarce data, no recommendation for the treatment of apraxia is provided ("There is insufficient evidence to support or refute the effectiveness of specific therapeutic interventions for motor apraxia after stroke", p. 2) [73].

While some studies report a positive effect of therapeutic intervention immediately after the intervention has been completed $[21,35,37,61,62,64]$, in most cases it remains questionable whether this positive effect is persistent. Only Smania and colleagues [62] reported that the positive effect of the intervention persisted at least for 2 months after the gesture training had been completed. Accordingly, based upon the above data, we currently recommend to treat apraxic patients with the gesture training. A detailed description of the gesture training is provided in Smania et al. [61]. Moreover, we encourage therapists to gear the ADLs trained during treatment sessions to the patient's individual environment, as in particular the transfer of the therapeutic effect to untrained activities as well as into different environments was only partially achieved by the hitherto published treatment approaches.

We hope that with the accomplishment of further prospective, randomized, controlled studies that investigate the efficacy of therapeutic interventions for apraxia, the data records will soon improve, so that apraxic patients can be treated more effectively in the future. The present review aims at directing the reader's attention to the clinical dimension of upper limb apraxia and thereby tries to prepare the basis for further therapy studies of the disabling syndrome of apraxia.
Conflicts of interest None.

Open Access This article is distributed under the terms of the Creative Commons Attribution Noncommercial License which permits any noncommercial use, distribution, and reproduction in any medium, provided the original author(s) and source are credited.

\section{References}

1. Alexander MP, Baker E, Naeser MA, Kaplan E, Palumbo C (1992) Neuropsychological and neuroanatomical dimensions of ideomotor apraxia. Brain 115:87-107

2. Almeida QJ, Black SE, Roy EA (2002) Screening for apraxia: a short assessment for stroke patients. Brain Cogn 48:253-258

3. Bartolo A, Cubelli R, Della Sala S, Drei S, Marchetti C (2001) Double dissociation between meaningful and meaningless gesture reproduction in apraxia. Cortex 37:696-699

4. Bartolo A, Cubelli R, Della Sala S (2008) Cognitive approach to the assessment of limb apraxia. Clin Neuropsych 22:27-45

5. Basso A, Capitani E, Della Sala S, Laiacona M, Spinnler H (1987) Recovery from ideomotor apraxia. A study on acute stroke patients. Brain 110:747-760

6. Bjorneby ER, Reinvang IR (1985) Acquiring and maintaining self-care skills after stroke. The predictive value of apraxia. Scand J Rehabil Med 17:75-80

7. Bonita R, Solomon N, Broad JB (1997) Prevalence of stroke and stroke-related disability. Estimates from the Auckland stroke studies. Stroke 10:1898-1902

8. Borod JC, Fitzpatrick PM, Helm-Estabrooks N, Goodglass H (1989) The relationship between limb apraxia and the spontaneous use of communicative gesture in aphasia. Brain Cogn 10: 121-131

9. Buxbaum LJ, Haal KY, Hallett M, Wheaton L, Heilman KM, Rodriguez A, Rothi LJG (2008) Treatment of limb apraxia: moving forward to improve action. Am J Phys Med Rehabil 87:149-161

10. Cappa SF, Benke T, Clarke S, Rossi B, Stemmer B, van Heugten CM (2005) EFNS guidelines on cognitive rehabilitation: report of an EFNS task force. Eur J Neurol 12:665-680

11. Code C, Gaunt C (1986) Treating severe speech and limb apraxia in a case of aphasia. British J Disord Commun 21:11-20

12. Coelho CA, Duffy RJ (1987) The relationship of the acquisition of manual signs to severity of aphasia: a training study. Brain Lang 31:328-345

13. Cubelli R, Trentini P, Montagna CG (1991) Re-education of gestural communication in a case of chronic global aphasia and limb apraxia. Cognit Neuropsychol 8:369-380

14. Cubelli R, Marchetti M, Boscolo G, Della Sala S (2000) Cognition in action: testing a model of limb apraxia. Brain Cogn 44:144-165

15. Daumüller M, Goldenberg G (2010) Therapy to improve gestural expression in aphasia: a controlled clinical trial. Clin Rehabil 24:55-65

16. De Renzi E, Pieczuro A, Vignolo LA (1968) Ideational apraxia: a quantitative study. Neuropsychologia 6:41-52

17. De Renzi E, Motti F, Nichelli P (1980) Imitating gestures. A quantitative approach to ideomotor apraxia. Arch Neurol 37:6-10

18. Demeurisse G, Demol O, Robaye E (1980) Motor evaluation in vascular hemiplegia. Eur Neurol 19:382-389

19. Dobigny-Roman N, Dieudonne-moinet B, Tortrat D, Verny M, Forette B (1998) Ideomotor apraxia test: a new test of imitation of gestures for elderly people. Eur J Neurol 5:571-578 
20. Donkervoort M, Dekker J, van den Ende E, Stehmann-Saris JC, Deelman BG (2000) Prevalence of apraxia among patients with a first left hemisphere stroke in rehabilitation centres and nursing homes. Clin Rehabil 14:130-136

21. Donkervoort M, Dekker J, Stehmann-Saris JC, Deelman BG (2001) Efficacy of strategy training in left hemisphere stroke patients with apraxia: a randomized clinical trial. Neuropsychol Rehabil 11:549-566

22. Dovern A, Fink GR, Saliger J, Karbe H, Koch I, Weiss PH (2011) Apraxia impairs intentional retrieval of incidentally acquired motor knowledge. J Neurosci 31:8102-8108

23. Dovern A, Fink GR, Weiss PH (2011) How to diagnose and treat limb apraxia. Fortschritte Neurologie Psychiatrie 79:345-357

24. Duffy JR, Duffy RJ (1990) The assessment of limb apraxia: the limb apraxia test. In: Hammond GR (ed) Cerebral control of speech and limb movements. North-Holland, Amsterdam

25. Feyereisen P, Barter D, Goossens M, Clerebraut N (1988) Gestures and speech in referential communication by aphasic subjects: channel use and efficiency. Aphasiology 2:21-32

26. Foundas AL, Macauley BL, Raymer AM, Maher LM, Heilman KM, Gonzalez Rothi LJ (1995) Ecological implications of limb apraxia: evidence from mealtime behavior. J Int Neuropsychol Soc 1:62-66

27. Frey SH, Fogassi L, Grafton S, Picard N, Rothwell JC, Schweighofer N, Corbetta M, Fitzpatrick SM (2011) Neurological principles and rehabilitation of action disorders: computation, anatomy, and physiology (CAP) model. Neurorehabil Neural Repair 25:6S-20S

28. Geusgens C, van Heugten CM, Donkervoort M, van den Ende E, Jolles J, van den Heuvel W (2006) Transfer of training effects in stroke patients with apraxia: an exploratory study. Neuropsycholog Rehabil 16:213-229

29. Giaquinto S, Buzzelli S, Di Francesco L, Lottarini A, Montenero P, Tonin P, Nolfe G (1999) On the prognosis of outcome after stroke. Acta Neurol Scand 100:202-208

30. Goldenberg G (1996) Defective imitation of gestures in patients with damage in the left or right hemispheres. J Neurol Neurosurg Psychiatry 61:176-180

31. Goldenberg G (2003) The neuropsychological assessment and treatment of disorders of voluntary movement. In: Halligan P, Kischka U, Marshall JC (eds) Handbook of clinical neuropsychology. Oxford University Press, Oxford, pp 387-400

32. Goldenberg G (2008) Apraxia. In: Goldenberg G, Miller BL (eds) Neuropsychology and behavioral neurology. Elsevier, Amsterdam, pp 323-338

33. Goldenberg G (2008) Apraxien. Aktuelle Neurologie 35:34-48

34. Goldenberg G, Hagmann S (1997) The meaning of meaningless gestures: a study of visuo-imitative apraxia. Neuropsychologia 35:333-341

35. Goldenberg G, Hagmann S (1998) Therapy of activities of daily living in patients with apraxia. Neuropsychol Rehabil 8:123-141

36. Goldenberg G, Hagmann S (1998) Tool use and mechanical problem solving in apraxia. Neuropsychologia 36:581-589

37. Goldenberg G, Daumüller M, Hagmann S (2001) Assessment and therapy of complex activities of daily living in apraxia. Neuropsychol Rehabil 11:147-169

38. Goldenberg G, Hartmann K, Schlott I (2003) Defective pantomime of object use in left brain damage: apraxia or asymbolia? Neuropsychologia 41:1565-1573

39. Goodglass H, Kaplan E (1972) Assessment of aphasia and related disorders. Lea and Febinger, Philadelphia

40. Hanna-Pladdy B, Heilman KM, Foundas AL (2003) Ecological implications of ideomotor apraxia. Neurology 60:487-490

41. Hermsdörfer J, Hentze S, Goldenberg G (2006) Spatial and kinematic features of apraxic movement depend on the mode of execution. Neuropsychologia 44:1642-1652
42. Kaya K, Unsal-Delialioglu S, Kurt M, Altinok N, Ozel S (2006) Evaluation of ideomotor apraxia in patients with stroke: a study of reliability and validity. J Rehabil Med 38:108-112

43. Kertesz A, Ferro JM (1984) Lesion size and location in ideomotor apraxia. Brain 107:921-933

44. Kertesz A, Hooper P (1982) Praxis and language: the extent and variety of apraxia in aphasia. Neuropsychologia 20:275-286

45. Kokmen E, Ozekmekci FS, Cha RH, O’Brien PJ (1998) Testing for apraxia in neurological patients: a descriptive study in two diverse cultures. Eur J Neurol 5:175-180

46. Liepelt I, Trenner MU, Freund S, Engel U, Lueschow A, Platz T (2007) Der Berliner-Apraxie-Test für ideomotorische und ideatorische Apraxie. Zeitschrift für Neuropsychologie 18:193-206

47. Lyle RC (1981) A performance test for assessment of upper limb function in physical rehabilitation treatment and research. Int $\mathrm{J}$ Rehabil Res 4:483-492

48. McDonald S, Tate RL, Rigby J (1994) Error types in ideomotor apraxia: a qualitative analysis. Brain Cogn 25:250-270

49. Poeck K (1986) The clinical examination for motor apraxia. Neuropsychologia 24:129-134

50. Power E, Code C, Croot K, Sheard C, Rothi LJG (2010) Florida apraxia battery-extended and revised Sydney (FABERS): design, description, and a healthy control sample. J Clin Exp Neuropsychol 32:1-18

51. Rossetti Y, Rode G, Goldenberg G (2005) Perspectives in higherorder motor deficit rehabilitation. Which approach for which ecological result? In: Freund H-J, Jeannerod M, Hallett M, Leiguarda R (eds) Higher-order motor disorders. From neuroanatomy and neurobiology to clinical neurology. Oxford University Press, Oxford, pp 475-498

52. Roßmüller J (2007) Theoriegeleitetes Assessment von Praxiefunktionen bei Schlaganfall-Patienten. Neurologie Rehabil 13:305-311

53. Rothi LJG, Heilman KM (1984) Acquisition and retention of gestures by apraxic patients. Brain Cogn 3:426-437

54. Rothi LJG, Mack L, Heilman KM (1986) Pantomime agnosia. J Neurol Neurosurg Psychiatry 49:451-454

55. Rothi LJG, Ochipa C, Heilman KM (1991) A cognitive neuropsychological model of limb praxis. Cogn Neuropsychol 8:443458

56. Rothi LJG, Ochipa C, Heilman KM (1997) A cognitive neuropsychological model of limb praxis and apraxia. In: Rothi LJG, Heilman KM (eds) Apraxia: the neuropsychology of action. Psychology Press, Hove, pp 29-49

57. Roy EA, Black SE, Blair N, Dimeck PT (1998) Analyses of deficits in gestural pantomime. J Clin Exp Neuropsychol 20:628643

58. Rumiati RI, Weiss PH, Tessari A, Assmus A, Zilles K, Herzog H, Fink GR (2005) Common and differential neural mechanisms supporting imitation of meaningful and meaningless actions. J Cogn Neurosci 17:1420-1431

59. Saeki S, Ogata H, Okubo T, Takahashi K, Hoshuyama T (1995) Return to work after stroke. Stroke 26:399-401

60. Schwartz MF, Segal M, Veramonti T, Ferraro M, Buxbaum LJ (2002) The naturalistic action test: a standardised assessment for everyday action impairment. Neuropsychol Rehabil 12:311-339

61. Smania N, Girardi F, Domenicali C, Lora E, Aglioti S (2000) The rehabilitation of limb apraxia: a study in left-brain-damaged patients. Arch Phys Med Rehabil 81:379-388

62. Smania N, Aglioti SM, Girardi F, Tinazzi M, Fiaschi A, Cosentino A, Corato E (2006) Rehabilitation of limb apraxia improves daily life activities in patients with stroke. Neurology 67:2050-2052

63. Sundet K, Finset A, Reinvang I (1988) Neuropsychological predictors in stroke rehabilitation. J Clin Exp Neuropsychol 10:363379 
64. van Heugten CM, Dekker J, Deelman BG, van Dijk AJ, Stehmann-Saris JC, Kinebanian A (1998) Outcome of strategy training in stroke patients with apraxia: a phase II study. Clin Rehabil 12:294-303

65. van Heugten CM, Dekker J, Deelman BG, Stehmann-Saris JC, Kinebanian A (1999) A diagnostic test for apraxia in stroke patients: internal consistency and diagnostic value. Clin Neuropsychol 13:182-192

66. van Heugten CM, Dekker J, Deelman BG, Stehmann-Saris JC, Kinebanian A (1999) Assessment of disabilities in stroke patients with apraxia: internal consistency and interobserver reliability. Occup Ther J Res 19:55-73

67. van Heugten CM, Dekker J, Deelman BG, van Dijk AJ, Stehmann-Saris JC, Kinebanian A (2000) Measuring disabilities in stroke patients with apraxia: a validation study of an observational method. Neuropsychol Rehabil 10:401-414

68. Vanbellingen T, Kersten B, Van de Winckel A, Bellion M, Baronti F, Müri R, Bohlhalter S (2011) A new bedside test of gestures in stroke: the apraxia screen of TULIA (AST). J Neurol Neurosurg Psychiatry 82(4):389-392
69. Vanbellingen T, Kersten B, Van Hemelrijk B, Van de Winckel A, Bertschi M, Müri R, De Weerdt W, Bohlhalter S (2010) Comprehensive assessment of gesture production: a new test of upper limb apraxia (TULIA). Eur J Neurol 17:59-66

70. Wade DT, Collin C (1988) The Barthel ADL Index: a standard measure of physical disability? Int Disabil Stud 10:64-67

71. Weiss PH, Kalbe E, Kessler J, Fink GR (in press) Das Kölner Apraxie Screening. Hogrefe Verlag, Göttingen

72. Weiss-Blankenhorn PH, Fink GR (2008) Neue Erkenntnisse zur Pathophysiologie der Apraxien durch funktionelle Bildgebung. Fortschritte Neurologie Psychiatrie 76:402-412

73. West C, Bowen A, Hesketh A, Vail A (2009) Interventions for motor apraxia following stroke. Cochrane Database Syst Rev. doi:10.1002/14651858.CD004132.pub2

74. Zwinkels A, Geusgens C, van de Sande P, van Heugten C (2004) Assessment of apraxia: inter-rater reliability of a new apraxia test, association of apraxia and other cognitive deficits and prevalence of apraxia in a rehabilitation setting. Clin Rehabil 18:819-827 